\title{
Caracterização pós-colheita de mamão armazenado em atmosfera modificada
}

\author{
Luiz F. G. Oliveira Jr. ${ }^{1}$, Enilce M. Coelho² \& Fábio C. Coelho ${ }^{3}$
}

\begin{abstract}
RESUMO
Através deste trabalho objetivou-se avaliar a vida pós-colheita de mamão, estudando-se o efeito da atmosfera modificada e absorvedor de etileno na qualidade dos frutos em três diferentes formas de armazenamento: frutos com embalagem de polietileno de baixa densidade (PEBD) e com absorvedor de etileno (CECA), frutos com embalagem de PEBD e sem absorvedor de etileno (CESA) e controle com frutos sem embalagem de PEBD e sem absorvedor de etileno (SE). Durante o período de armazenamento e a cada três dias, realizaram-se as seguintes análises: sólidos solúveis totais (SST), acidez titulável (AT), a razão entre SST e AT, firmeza da polpa (F) e análise sensorial, na qual foi avaliada a aceitação do produto para os atributos aroma, sabor, textura, cor da polpa e aparência. Os resultados obtidos mostraram, quanto à aceitabilidade, que os tratamentos diferiram entre si e também ao longo do período de armazenamento; para se armazenar mamões da cultivar Golden, a temperatura ambiente, é importante à utilização de embalagem de PEBD associada ao absorvedor de etileno, cujo efeito favoreceu a obtenção de frutos de qualidade, mantendo suas características físicas, químicas e sensoriais.
\end{abstract}

Palavras-chave: absorvedor de etileno, filme de PEBD, qualidade, análise sensorial

\section{Postharvest characterization of stored papaya in modified atmosphere}

\begin{abstract}
This work aimed to evaluate the postharvest quality of papaya, studyng the effects of modified atmosphere and of ethylene absorbers on fruit quality with three different modes of storage: fruits covered with film of PEBD and ethylene absorbers (CECA), fruits covered with film of PEBD without addition of ethylene absorbers (CESA) and, the control without film of PEBD and without addition of ethylene absorbers (SE). The following analyses were accomplished every 3 days during storage period: total soluble solid (TSS), titratable acidity (TA), the ratio between TSS and TA, pulp firmness and sensory analysis to evaluate the product approval according to attributes like aroma, taste, texture, color pulp and aspect. The obtained results showed differences in treatments as well as along the storage period. It was also noticed that storing papaya of the Golden cultivar in the ambient temperature, the use of packing associated with PEBD and ethylene absorbers is important because the associated effect favored the production of fruits with high quality, maintaining the physical, chemical and sensorial characteristics.
\end{abstract}

Key words: ethylene absorbers, film of PEBD, quality, sensory evaluation

${ }^{1}$ UFES. Av. Fernando Ferrari, 514, CEP 29060-900, Vitória, ES. Fone (27) 3335 7610. E-mail: Ifg@pesquisador.cnpq.br

2 LTA/UENF. Fone: (22) 27261461. E-mail: enilce@uenf.br

${ }^{3}$ LFIT/UENF. Fone (22) 27261428. E-mail: fcoelho@uenf.br 


\section{INTRODUÇÃO}

O fruto do mamoeiro é uma estrutura viva, composta de células metabolicamente ativas, enquanto ligado à planta; recebe água, nutrientes, sais minerais, hormônios e outros compostos. É fonte de carboidratos, vitaminas (principalmente C e A), fibra, potássio e pequenas quantidades de proteínas, gorduras, cálcio e sódio, além de fornecer cor, sabor, aroma e textura para a dieta humana (Fennema, 1996).

Dentre as características gustativas mais importantes que interferem no sabor e aceitação dos mamões, tem-se: o teor de sólidos solúveis e a acidez titulável. E o que determina a qualidade e o consumo dos frutos de mamão são as características sensoriais, como a cor, que é fator muito importante no julgamento inicial da qualidade do produto pelo consumidor (Yada \& Coffin, 1987; Loiselle et al., 1990), seguido da textura, que pode desagradar o consumidor, se não adequada ao alimento; por fim mas não menos significativo, o sabor (Lawless \& Heymann, 1998) decisivo na compra.

O sabor doce do mamão, em conjunto com mudanças da coloração e textura, é um dos principais parâmetros de qualidade que podem ser avaliados através da análise sensorial. Dentre os métodos sensoriais disponíveis para se medir a aceitação e preferência dos consumidores com relação a um ou mais produtos, está a escala hedônica estruturada de nove pontos; trata-se, provavelmente, do método afetivo mais utilizado devido à confiabilidade e validade de seus resultados e sua simplicidade em ser utilizada pelos provadores (Stone \& Sidel, 1993). Os dados obtidos através do teste de aceitação são submetidos a uma análise de variância (Anova) seguida de outros procedimentos estatísticos, dentre os quais o teste de Tukey, que permite verificar se há diferença significativa entre duas médias, a dado nível de confiança, normalmente 95\% (Meilgaard et al., 1987; Stone \& Sidel, 1993).

Para se manter a qualidade e prolongar a vida pós-colheita de frutos, utilizam-se algumas técnicas que limitam a disponibilidade de oxigênio. A embalagem com atmosfera modificada (EAM) reduz as taxas de respiração e produção de etileno, retarda o amolecimento e o amadurecimento (para frutos climatéricos) e outras alterações que ocorrem no produto (Chaplin et al., 1982; Miller et al., 1983; Yuen et al., 1993; Rodov et al.,1997) por meio de criação e manutenção de uma micro atmosfera ótima (geralmente com baixos níveis de $\mathrm{O}_{2}$ e altos níveis de $\mathrm{CO}_{2}$ ) dentro da embalagem ( $\mathrm{Za-}$ gory \& Kader, 1988; Lee et al., 1991).

'Backcross Solo' (papaya) embalados com três camadas de polietileno de baixa densidade (PEBD 0,0125 mm), foram armazenados a $24-28^{\circ} \mathrm{C}$ por 18 dias verificando-se atraso no desenvolvimento da cor da casca, amolecimento do fruto e redução no incremento de acidez titulável, quando comparado com o controle (Lazan et al., 1990). Constatouse, também, que pimentas acondicionadas e armazenadas a $8{ }^{\circ} \mathrm{C}$ e $88-92 \%$ de umidade relativa, em filme de polietileno de baixa densidade com $70 \mu \mathrm{m}$ de espessura apresentaram, em seu amadurecimento, um retardo de 10 dias, quando comparadas com as pimentas armazenadas fora da embalagem (Pala et al., 1994). Morangos submetidos a atmosfera modificada contendo absorvedor de etileno $\left(\mathrm{KMnO}_{4}\right)$, armazena- dos a baixas temperaturas, apresentaram decréscimo na taxa respiratória e aumento da vida de prateleira de 20 para 30 dias (Hao \& Hao, 1993).

A utilização de absorvedores de etileno associados à atmosfera modificada, é uma metodologia muito eficiente para se aumentar a vida de prateleira. Objetivou-se, com este trabalho, avaliar a vida pós-colheita de mamões, verificandose o efeito de diferentes formas de armazenamento nos atributos físico-químicos e sensoriais, ao longo do tempo.

\section{MATERIAL E MÉTODOS}

Os frutos do mamoeiro foram fornecidos pela Caliman Agrícola S.A., de Linhares, ES, em caixas de papelão (tipo exportação) contendo nove frutos, com peso individual médio de $400 \mathrm{~g}$.

As caixas que abrigaram esses frutos, foram submetidas aos seguintes tratamentos: frutos embalados com filme de polietileno de baixa densidade (PEBD) e absorvedor de etileno (sache contendo 9 gramas de permanganato de potássio, $\mathrm{KMnO}_{4}$ ) (CECA); frutos embalados com filme de PEBD e sem absorvedor de etileno (CESA) e sem filme de PEBD e sem absorvedor de etileno (SE). As caixas de papelão foram envolvidas em sacos de polietileno de baixa densidade, com espessura de $30 \mu \mathrm{m}$ (PEBD-30 $\mu \mathrm{m}$ ), com dimensão de 65 x $40 \mathrm{~cm}$, tendo como característica do filme sua taxa de permeabilidade ao oxigênio e ao gás carbônico a $20^{\circ} \mathrm{C}$ de 6800 e $30500 \mathrm{~mL} \mathrm{~m}^{-2} 24 \mathrm{~h}^{-1} \mathrm{~atm}^{-1}$, respectivamente, e armazenadas durante 12 dias, a temperatura de $25 \pm 2{ }^{\circ} \mathrm{C}$.

A cada três dias foram retiradas amostras de todos os tratamentos, para as seguintes análises: a) sólidos solúveis totais (SST), obtido por meio de homogeneização da polpa, de onde uma gota foi retirada e colocada na lente do refratômetro digital Atago, modelo PR 201, e o valor obtido expresso em ${ }^{\circ}$ Brix; b) acidez titulável (AT), obtida pela titulação de uma alíquota de suco com solução de $\mathrm{NaOH}$ a $0,1 \mathrm{~N}$, em presença de fenolftaleína, até atingir um $\mathrm{pH}$ 8,0, expressando-se os resultados em $\mathrm{mg}$ de ácido cítrico/100 mL de suco (AOAC, 1992); c) razão entre SST e AT; d) firmeza da polpa do fruto $(F)$, em que, após retirada da casca para exposição da polpa, os frutos foram submetidos a pressão em três pontos eqüidistantes na região mediana, medindo-se a resistência da polpa à penetração, utilizando-se penetrômetro digital, marca TR Turoni, modelo 53205, e o valor obtido expresso em Newton (N).

Realizou-se também, a cada três dias, análise sensorial dos mamões apresentados a 30 potenciais consumidores, em que pedaços de mamão foram colocados em copinhos descartáveis de plástico neutro, codificados com algarismos de três dígitos e servidos aos julgadores na ordem de apresentação indicada pelo delineamento experimental. Entre uma amostra e outra, para limpeza do palato, serviu-se água a temperatura ambiente.

Quanto à aceitabilidade, solicitou-se, aos julgadores, que indicassem quanto gostaram ou desgostaram do produto em relação: à aparência externa, cor da polpa, aroma, sabor e 
textura/sensação na boca, utilizando-se uma escala hedônica de 9 pontos, variando de "gostei extremamente" a "desgostei extremamente” (Stone \& Sidel, 1993).

Para a análise estatística utilizou-se o delineamento em blocos casualizados com três repetições em um esquema fatorial $3 \times 4$, cujos fatores e níveis foram tratamentos (CECA, CESA e SE) e períodos de armazenamento (3, 6, 9 e 12), totalizando 36 caixas de mamões. A unidade experimental consistiu de uma caixa de mamão contendo nove frutos, da qual foram retirados três frutos, aleatoriamente, para análises físicas, químicas e sensoriais.

\section{RESULTADOS E DISCUSSÃO}

A variável que exprime a relação entre SST/AT, pode indicar com certo grau de precisão, o estádio de desenvolvimento em que os frutos se encontram, principalmente se forem assessorados pela firmeza da polpa, SST e AT. Com relação aos três tratamentos, é possível se distinguir comportamentos e estádios de maturação distintos (Tabela 1).

Tabela 1. Valores médios da acidez titulável (AT), sólidos solúveis totais (SST), relação SST/AT e firmeza da polpa do fruto (F) de mamão cv. Golden, armazenado a temperatura ambiente

\begin{tabular}{|c|c|c|c|c|}
\hline & \multicolumn{4}{|c|}{ Período de Armazenamento (dias) } \\
\hline & 3 & 6 & 9 & 12 \\
\hline Tratamento & \multicolumn{4}{|c|}{ AT mg de ácido cítrico (100 mL de suco $)^{-1}$} \\
\hline CECA & $0,10 \mathrm{Bc}$ & $0,11 \mathrm{Ac}$ & $0,11 \mathrm{Ab}$ & $0,11 \mathrm{Aa}$ \\
\hline CESA & $0,11 \mathrm{Bb}$ & $0,12 \mathrm{Ab}$ & $0,12 \mathrm{Aa}$ & $0,09 \mathrm{Cb}$ \\
\hline SE & $0,13 \mathrm{Aa}$ & $0,13 \mathrm{Aa}$ & $0,11 \mathrm{Bb}$ & $0,09 \mathrm{Cb}$ \\
\hline Tratamento & \multicolumn{4}{|c|}{ SST ( ${ }^{\circ}$ Brix) } \\
\hline CECA & $12,80 \mathrm{Cc}$ & $13,68 \mathrm{Bb}$ & $13,76 \mathrm{Ba}$ & $14,07 \mathrm{Aa}$ \\
\hline CESA & $13,97 \mathrm{Ab}$ & $13,63 \mathrm{Ab}$ & $13,66 \mathrm{Aa}$ & $13,76 \mathrm{Ab}$ \\
\hline SE & $15,01 \mathrm{Aa}$ & $14,03 \mathrm{Ba}$ & $12,88 \mathrm{Cb}$ & $12,69 \mathrm{Cc}$ \\
\hline Tratamento & \multicolumn{4}{|c|}{ SST/AT } \\
\hline CECA & $123,08 \mathrm{Aa}$ & $124,36 \mathrm{Aa}$ & $125,09 \mathrm{Aa}$ & $134,77 \mathrm{Ab}$ \\
\hline CESA & $123,63 \mathrm{Ba}$ & $113,58 \mathrm{Bb}$ & $113,83 \mathrm{Bb}$ & $152,89 \mathrm{Aa}$ \\
\hline SE & $112,01 \mathrm{Cb}$ & $112,24 \mathrm{Cb}$ & $122,67 \mathrm{Ba}$ & $145,86 \mathrm{Aa}$ \\
\hline Tratamento & \multicolumn{4}{|c|}{$\mathrm{F}(\mathrm{N})$} \\
\hline CECA & $50,05 \mathrm{Aa}$ & $35,97 \mathrm{Ca}$ & $42,03 \mathrm{Ba}$ & $40,09 \mathrm{Ba}$ \\
\hline CESA & $20,87 \mathrm{Ab}$ & $15,69 \mathrm{Bb}$ & $18,34 \mathrm{ABb}$ & $5,61 \mathrm{Cb}$ \\
\hline SE & $14,62 \mathrm{Ac}$ & $9,98 \mathrm{ABC}$ & $7,30 \mathrm{BCC}$ & $4,29 \mathrm{Db}$ \\
\hline
\end{tabular}

*As médias seguidas por pelo menos uma mesma letra, minúscula nas colunas e maiúscula nas linhas, não diferem entre si, a $5 \%$ de probabilidade, pelo teste $t$

Observou-se, na Tabela 1 para o tratamento SE, incremento do terceiro ao $12^{\circ}$ dia para os valores da relação SST/AT (de 112,01 a 145,86), em virtude da maior redução da AT e do SST. Entre os terceiro e sexto dias, pode-se verificar o melhor ponto de consumo do mamão. Segundo Fonseca et al. (2003) um bom indicativo de amadurecimento é quando o fruto se encontra com alto SST (15,01 e 14,03 ${ }^{\circ}$ Brix) e ligeiro decréscimo ou estabilidade de AT (0,13 e 0,13 mg de ácido cítrico (100 mL de suco $)^{-1}$. Com relação à firmeza da polpa, constatou-se decréscimo nos valores (de 14,62 para 9,98 N) indicando amaciamento e ponto de consumo. Segundo Paull \& Chen (1983) e Chan Jr. et al. (1981) a perda de firmeza é atribuída principalmente à atividade de enzimas responsáveis pela degradação da parede celular, como pectinametilesterase (PME) e poligalacturonase (PG). No $12^{\circ}$ dia constataram-se valores extremos para os frutos, apresentando maior relação SST/AT (145,86), forte decréscimo da AT (0,09 mg de ácido cítrico (100 mL de suco $)^{-1}$, SST (12,09 ${ }^{\circ}$ Brix) e firmeza da polpa $(4,29 \mathrm{~N})$, indicando que os frutos já estavam impróprios para o consumo, em maior grau de senescência.

Para o tratamento CESA, observou-se queda seguida por incremento de SST/AT, não havendo alteração significativa no SST ao longo do tempo. Esta constância foi, provavelmente, devido ao retardo no amadurecimento, em virtude da redução do metabolismo ocasionado pela atmosfera modificada passiva. Sem alteração do SST, o comportamento da relação SST/AT foi regido pela AT, que apresentou incremento seguido de decréscimo, cuja provável explicação para este comportamento se deu, em parte, ao acúmulo de ácidos orgânicos produzidos por enzimas que degradam a parede celular, como PME e PG, e o decréscimo da AT foi em função da utilização do mesmo, em diversas rotas metabólicas. Mosca \& Durigan (1995) e Simão (1971) ao trabalharem com mamões cv Sunrise Solo line 72/12, observaram as mesmas tendências para SST, embora os valores se diferenciem em virtude dos estádios de maturação, nos quais os frutos foram armazenados e, principalmente, por se tratar de cultivares diferentes.

Quanto à melhor data para o consumo dos frutos para o tratamento CESA, ficaria entre o $9^{\circ}$ e o $12^{\circ}$ dia, pois apresentam alto SST (13,66 e 13,76 $\left.{ }^{\circ} \mathrm{Brix}\right)$, estabilidade a queda de AT (0,12 e 0,09 mg de ácido cítrico (100 mL de suco $)^{-1}$ e redução na firmeza (18,34 e 5,61 N) verificando-se, assim, amadurecimento no $9^{\circ}$ dia e senescência no $12^{\circ}$ dia. Resultados semelhantes aos deste trabalho, foram encontrados por Carvalho et al. (2001) com goiabas, em que os frutos embalados apresentaram firmeza superior aos frutos controle.

À primeira vista, os dados da relação SST/AT para o tratamento CECA sugerem senescência, tal como ocorreu no tratamento SE mas, em função do constante acúmulo de SST e do não decréscimo de AT, verifica-se o amadurecimento. Desta forma, a data mais provável para o consumo seria no $12^{\circ}$ dia, visto que o fruto apresenta maior SST (14,07 $\left.{ }^{\circ} \mathrm{Brix}\right)$, AT $\left(0,11 \mathrm{mg}\right.$ de ácido cítrico $\left.(100 \mathrm{~mL} \text { de suco })^{-1}\right)$ e firmeza da polpa relativamente alta em comparação com os demais tratamentos (40,09 N). Cenci et al. (1999) observaram a mesma superioridade para firmeza da polpa do mamão, apresentada quando utilizaram absorvedor sem embalagem.

Observam-se, na Tabela 2, os resultados dos testes de aceitação de consumidor em laboratório, que utilizaram a escala hedônica para avaliar o aroma, sabor, cor da polpa, textura e aparência externa, característicos do mamão, em seus tratamentos.

Os atributos sabor, textura e aparência externa, foram os que melhor caracterizaram o ponto de consumo e aceitabilidade do mamão, pelos provadores podendo, também, ser avaliados pela razão entre sólidos solúveis totais e acidez titulável, que é uma característica que reflete a qualidade sensorial de frutos, conhecida como índice de maturidade (Agustí, 2000). 
Tabela 2. Análise sensorial do mamão nos diferentes tratamentos para os atributos aroma, sabor, textura, cor da polpa e aparência externa

\begin{tabular}{|c|c|c|c|c|}
\hline & \multicolumn{4}{|c|}{ Período de Armazenamento (dias) } \\
\hline & 3 & 6 & 9 & 12 \\
\hline Tratamento & \multicolumn{4}{|c|}{ Aroma (notas) } \\
\hline CECA & $6,47 \mathrm{Aa}$ & 6,30 Aba & $4,27 \mathrm{Cc}$ & $6,23 \mathrm{Bb}$ \\
\hline CESA & $6,57 \mathrm{Aa}$ & $5,73 \mathrm{Cb}$ & $4,90 \mathrm{Db}$ & $6,00 \mathrm{Bb}$ \\
\hline SE & $6,73 \mathrm{Ba}$ & $6,50 \mathrm{Ba}$ & $6,97 \mathrm{Aa}$ & $6,60 \mathrm{Ba}$ \\
\hline Tratamento & \multicolumn{4}{|c|}{ Sabor (notas) } \\
\hline CECA & $5,20 \mathrm{Cc}$ & $5,70 \mathrm{Bb}$ & $5,73 \mathrm{Bb}$ & $6,80 \mathrm{Aa}$ \\
\hline CESA & $6,00 \mathrm{Bb}$ & 4,03 Cc & $6,27 \mathrm{Aa}$ & $6,40 \mathrm{Ab}$ \\
\hline SE & $6,47 \mathrm{Aa}$ & $6,05 \mathrm{Ba}$ & $5,20 \mathrm{Cc}$ & $5,13 \mathrm{Cc}$ \\
\hline Tratamento & \multicolumn{4}{|c|}{ Textura (notas) } \\
\hline CECA & $6,2 \mathrm{Ac}$ & $5,83 \mathrm{Ba}$ & $5,2 \mathrm{Cb}$ & $6,00 \mathrm{ABb}$ \\
\hline CESA & $6,7 \mathrm{Ab}$ & $4,83 \mathrm{Cb}$ & $5,87 \mathrm{Ba}$ & 6,83 $\mathrm{Aa}$ \\
\hline SE & $7,6 \mathrm{Aa}$ & $4,93 \mathrm{Bb}$ & $5,03 \mathrm{Bb}$ & $5,03 \mathrm{Bc}$ \\
\hline Tratamento & \multicolumn{4}{|c|}{ Cor da polpa (notas) } \\
\hline CECA & $6,93 \mathrm{Aa}$ & 6,50 Ba & $5,03 \mathrm{Cc}$ & $6,13 \mathrm{Cb}$ \\
\hline CESA & $6,47 \mathrm{Bb}$ & $6,70 \mathrm{Aa}$ & $6,20 \mathrm{Cb}$ & $6,57 \mathrm{ABa}$ \\
\hline SE & 6,33 Bb & $6,53 \mathrm{Ba}$ & $7,20 \mathrm{Aa}$ & $6,57 \mathrm{Ba}$ \\
\hline Tratamento & \multicolumn{4}{|c|}{ Aparência externa (notas) } \\
\hline CECA & 6,37 Bb & $6,10 \mathrm{Ca}$ & $6,33 \mathrm{Ba}$ & $6,63 \mathrm{Aa}$ \\
\hline CESA & $7,27 \mathrm{Aa}$ & $6,00 \mathrm{Ba}$ & $6,03 \mathrm{Bb}$ & $4,73 \mathrm{Cb}$ \\
\hline SE & $6,60 \mathrm{Ab}$ & $5,33 \mathrm{Bb}$ & $4,30 \mathrm{Cc}$ & 3,03 Dc \\
\hline
\end{tabular}

${ }^{*}$ As médias seguidas por pelo menos uma mesma letra, minúsculas nas colunas e maiúsculas nas linhas, não diferem entre si, a $5 \%$ de probabilidade, pelo teste $t$

Para o tratamento SE durante os 12 dias de armazenamento, e segundo os provadores, o dia que melhor caracterizou o fruto para o consumo, foi o $3^{\circ}$ dia, com nota 6,47 para sabor, 7,6 para textura e 6,6 para aparência externa, correspondendo às melhores notas, durante o armazenamento. Neste dia, os frutos se encontravam com elevado SST, AT estável, baixa relação SST/AT e firmeza (F) média, ou seja com excelente grau de maturação. Para os períodos subseqüentes, as notas apresentadas pelos provadores foram reduzindo com o avanço da senescência. Quanto ao aroma e à cor da polpa, os provadores indicaram a melhor nota para o $9^{\circ}$ dia.

No tratamento CESA, as melhores notas se encontraram entre os $9^{\circ}$ e $12^{\circ}$ dias de armazenamento, sugerindo melhor data de consumo, também em função do melhor amadurecimento, alto SST e baixo AT, com notas 6,27 e 6,40 para sabor e 5,87 e 6,83 para textura; para aparência externa o dia menos aceito foi o $12^{\circ}$ dia, com 4,73. Para aroma, as maiores notas pertenceram ao $3^{\circ}$ dia, enquanto para cor da polpa foi ressaltado o $6^{\circ}$ dia.

Com o retardo do amadurecimento promovido pela embalagem e absorvedor de etileno, o tratamento CECA apresentou provável data para consumo de mamão com qualidade; segundo os provadores, no $12^{\circ}$ dia de armazenamento, com notas 6,80 para sabor, 6,00 para textura e 6,63 para aparência externa. Para sabor e aparência, no $12^{\circ}$ dia o tratamento CECA foi superior aos demais tratamentos; quanto à textura, a aceitação foi inferior no tratamento CESA, em função da menor maciez. O efeito do absorvedor de etileno retardou o amaciamento da polpa, apresentando maior firmeza no tratamento CECA $(40,09 \mathrm{~N})$ que no CESA $(5,61 \mathrm{~N})$, e maior nota para textura o tratamento CESA
$(6,83)$ indicando que os provadores preferem a polpa de mamão menos firme. A preferência para o aroma e cor da polpa para o tratamento CECA, situou-se no $3^{\circ}$ dia, com as maiores notas.

\section{CONCLUSÕES}

1. De acordo com os dados das análises físicas, químicas e sensoriais, foi possível caracterizar e estabelecer períodos ideais para o consumo de mamão cv. Golden nos diferentes tratamentos.

2. Verificou-se que o ponto de consumo para mamões sem a utilização de embalagem se encontra entre três e seis dias, mantendo-se as características físicas, químicas e sensoriais.

3. Quando se deseja prolongar o período de armazenamento para nove dias mantendo-se as características físicas, químicas e sensoriais, basta fazer a utilização de filme de polietileno de baixa densidade (PEBD).

4. Para um período de 12 dias a temperatura ambiente, além de se fazer uso do filme PEBD é necessário utilizar-se absorvedor de etileno, para manter as características físicas, químicas e sensoriais.

\section{LITERATURA CITADA}

Agustí, M. Crecimiento y maduración del fruto. In: Azcón-Bieto, J.; Talón, M. Fundamentos de fisiología vegetal. Barcelona: Edicions Universitat de Barcelona, 2000. cap.6, p.419-433.

AOAC - Association of Official Analytical Chemists. Official methods of analysis of the association of official analytical chemistry, 11.ed. Washington: DC: AOAC, 1992. 1115p.

Carvalho, H. A.; Chitarra, A. B.; Chitarra, M. I. F. Efeito da atmosfera modificada sobre componentes da parede celular da goiaba. Ciência Agrotécnica, Lavras, v.25, n.3, p.605615, 2001.

Cenci, S. A.; Soares, A. G.; Sousa, M. L. Efecto de la aplicación de absorvedor de etileno $\mathrm{KMnO}_{4}$ en las características de calidad y conservación de la papaya cv. Sunrise. Revista Iber. Tecnologia Postcosecha, Santiago, v.1, n.2, p.150155, 1999.

Chan Jr., H. T.; Tam, S. Y. T.; Seo, S. T. Papaya poligalacturonase and its role in thermally injured ripening fruit. Journal of Food Science, Chicago, v.46, n.1, p.190-197, 1981.

Chaplin, G. R.; Scott, K. J.; Brown, B. I. Effects of storing mangoes in polyethylene bags at ambient temperature. Singapore Journal of Primary Industry, Singapore, v.10, n.2, p.84-89, 1982.

Fennema, O. R. Food chemistry. 3.ed. New York: Marcel Dekker, 1996, 1069p.

Fonseca, M. J. O.; Cenci, A. S.; Botrel, N.; Leal, N. R. Uso de atmosfera controlada na conservação de frutos de mamoeiro 'Sunrise Solo'. Revista Brasileira de Armazenamento, Viçosa, v.28, n.2, p.17-22, 2003.

Hao, H. P.; Hao, L. Study on storing strawberry at a temperature near the freezing point of water. Journal of Fruit Science, Haworth, v.10, n.1, p.21-24, 1993. 
Lawless, H.; Heymann, H. Sensory evaluation of food-principles and practices. New York: Chapman \& Hall, 1998. 827p.

Lazan, H.; Ali, Z. M.; Sim, W. C. Retardation of ripening and development of water stress in papaya fruit seal-packaged with polyethylene film. Acta Horticulturae, Wageningen v.269, n.1, p.345-358, 1990.

Lee, D. S.; Haggar, P. E.; Lee, J.; Yam, K. L. Model for fresh produce respiration in modified atmospheres based on principle of enzyme kinetics. Journal of Food Science, Chicago, v.56, n.6, p.1580-1585, 1991.

Loiselle, F.; Tai, G. C. C.; Christie, B. R. Genetic components of chip color evaluated after harvest, cold storage and reconditioning. American Potato Journal, Nebraska, v.67, n.9, p.633646, 1990.

Meilgaard, M.; Civille, G. V.; Carr, B. T. Sensory evaluation techniques. Boca Raton: CRC Press, Inc., 1987. 302p.

Miller, W. R.; Hale, P. W.; Spalding, D. H.; Davis, P. Quality and decay of mango fruit wrapped in heat-shrinkable film. HortScience, Alexandria, v.18, n.6, p.957-958, 1983.

Mosca, J. L.; Durigan, J. F. Post-harvesting conservation of papaya fruits Carica papaya L 'Improved sunrise solo line 72/ 12', with utilization of protector films and Was, associated with refrigeration. Acta Horticulturae, Wageningen, v.370, n.1, p.217-221, 1995.
Pala, M.; Damarli, E.; Alikasifoglu, K. A study of quality parameters in green pepper packaged in polymeric films. In Symposium International of Refrigeration, 1994, Istanbul. Anais... Istambul: quem publicou? 1994. p.305-316.

Paull, R. E.; Chen, N. J. Post-harvest variation in cell wall degrading enzymes of papaya (Carica papaya L.) during fruit repining. Plant Physiology, Lancaster, v.72, n.1, p.382-385, 1983.

Rodov, V.; Fishman, S.; de La Asunción, R.; Peretz, J.; Ben Yehoshua, S. Modified atmosphere packaging (MAP) of 'Tommy Atckins' mango in perfored films. Acta Horticulturae, Wageningen v.455, n.1, p.654-661, 1997.

Simão, S. Manual de fruticultura. São Paulo: Agronômica Ceres, 1971, 521p.

Stone, H. S.; Sidel, J. L. Sensory evaluation practices. San Diego: Academic Press, 1993. 308p.

Yada, R. Y.; Coffin, R. H. Crispy, crunchy and mitritious improving cultivaars for potato chips. Highlights of Agricultural Research, Alabama, v.10, n.2, p.1-23, 1987.

Yuen, C. M. C.; Tan, S. C.; Joyce, D.; Chettri, P. Effect of postharvest calcium and polymeric films on ripening and peel injury in 'Kensington Piule' mango. Asean Food Journal, Melbourne, v.8, n.4, p.110-113, 1993.

Zagory, D.; Kader, A. A. Modified atmosphere packaging of fresh produce. Food Technology, Chicago, v.42, n.9, p.70-77, 1988. 